\title{
BMJ Open Estimating the prevalence, hospitalisation and mortality from type 2 diabetes mellitus in Nigeria: a systematic review and meta-analysis
}

\author{
Davies Adeloye, ${ }^{1,2}$ Janet O Ige, ${ }^{3}$ Adewale V Aderemi, ${ }^{4}$ Ngozi Adeleye, ${ }^{5}$ \\ Emmanuel O Amoo, ${ }^{1}$ Asa Auta, ${ }^{6}$ Gbolahan Oni ${ }^{1}$
}

To cite: Adeloye $\mathrm{D}$, Ige $\mathrm{J} 0$, Aderemi AV, et al. Estimating the prevalence, hospitalisation and mortality from type 2 diabetes mellitus in Nigeria: a systematic review and meta-analysis. BMJ Open 2017;7:e015424. doi:10.1136/ bmjopen-2016-015424

- Prepublication history and additional material is available. To view please visit the journal (http://dx.doi.org/ 10.1136/ bmjopen-2016-015424)

Received 2 December 2016 Revised 25 February 2017 Accepted 30 March 2017

CrossMark

${ }^{1}$ Demography and Social Statistics, Covenant University, Ota, Nigeria

${ }^{2}$ Centre for Global Health Research, Usher Institute, University of Edinburgh,

Edinburgh, UK

${ }^{3}$ Faculty of Health and Applied

Sciences, University of the West of England, Bristol, UK

${ }^{4}$ Department of Biochemistry,

College of Health Sciences,

Osun State University, Osogbo,

Nigeria

${ }^{5}$ Economics and Development Studies, Covenant University,

Ota, Nigeria

${ }^{6}$ School of Pharmacy and Biomedical Sciences, University of Central Lancashire, Preston, UK

Correspondence to

Dr Davies Adeloye;

bummyadeloy@gmail.com

\section{ABSTRACT}

Background There is not yet a comprehensive evidencebased epidemiological report on type 2 diabetes mellitus (T2DM) in Nigeria. We aimed to estimate country-wide and zonal prevalence, hospitalisation and mortality rates of T2DM in Nigeria.

Methods We searched MEDLINE, EMBASE, Global Health, Africa Journals Online (AJOL) and Google Scholar for population and hospital-based studies on T2DM in Nigeria. We conducted a random-effects meta-analysis on extracted crude estimates, and applied a meta-regression epidemiological model, using the United Nations demographics for Nigeria in 1990 and 2015 to determine estimates of diabetes in Nigeria for the two years.

Results 42 studies, with a total population of 91320 , met our selection criteria. Most of the studies selected were of medium quality (90.5\%). The age-adjusted prevalence rates of T2DM in Nigeria among persons aged 20-79 years increased from $2.0 \%(95 \% \mathrm{Cl} 1.9 \%$ to $2.1 \%)$ in 1990 to $5.7 \%(95 \% \mathrm{Cl} 5.5 \%$ to $5.8 \%)$ in 2015 , accounting for over 874000 and 4.7 million cases, respectively. The pooled prevalence rate of impaired glucose tolerance was $10.0 \%$ (95\% Cl $4.5 \%$ to $15.6 \%)$, while impaired fasting glucose was $5.8 \%(95 \% \mathrm{Cl} 3.8 \%$ to $7.8 \%)$. Hospital admission rate for T2DM was 222.6 (95\% Cl 133.1 to 312.1) per 100000 population with hyperglycaemic emergencies, diabetic foot and cardiovascular diseases being most common complications. The overall mortality rate was 30.2 (95\% Cl 14.6 to 45.8$)$ per 100000 population, with a case fatality rate of $22.0 \%$ ( $95 \% \mathrm{Cl} 8.0 \%$ to $36.0 \%)$.

Conclusion Our findings suggest an increasing burden of T2DM in Nigeria with many persons currently undiagnosed, and few known cases on treatment.

\section{INTRODUCTION}

Many studies have reported increasing prevalence of type 2 diabetes mellitus (T2DM) globally. ${ }^{1-3}$ According to International Diabetes Federation (IDF), there were over 151 million people with diabetes in $2000,{ }^{1}$ 194 million in $2003,{ }^{2} 246$ million in $2006,{ }^{3}$ 285 million in $2010^{45}$ and 415 million in 2015 . $^{6}$ The WHO reported that people living with diabetes globally increased from 108 million

\section{Strengths and limitations of this study}

- This study provides a comprehensive report on the epidemiology of type 2 diabetes mellitus (T2DM) in Nigeria since the last nationwide survey of noncommunicable diseases in 1997.

- Estimates provided are based on original population and hospital-based studies on type 2 diabetes conducted across the six geopolitical zones of Nigeria.

- The study is limited by lack of data on T2DM in northern parts of Nigeria, suggesting the need for more research in the region.

in 1980 to 422 million in 2014, with overweight and obesity being major risk factors. ${ }^{7}$ This increase was also observed in Africa, with diabetes cases increasing from 4 million to 25 million between 1980 and $2014 .^{7}$ Research findings have shown that prevalence rates of diabetes in urban Africa are in fact similar with, or even higher than, what is obtained in some developed countries. ${ }^{89}$ This has been linked to rapidly changing demographic trends, increased rate of urbanisation, unhealthy diets and gradual adoption of Western lifestyles in many African settings. ${ }^{10}$

In Nigeria, the most populous country in Africa, the prevalence of T2DM has been high and still increasing, with the country widely reported as having Africa's highest burden of diabetes. ${ }^{10}{ }^{11}$ However, there are no known country-wide surveys or any reported attempt within Nigeria in recent times to specifically estimate the burden of diabetes in the country. The last national survey of non-communicable diseases (NCDs) was conducted in 1997 with a prevalence of $2.2 \%$ reported for diabetes, ${ }^{12}$ and the 2003 national NCDs survey was mainly in the South-West region and results were inconclusive. ${ }^{13}$ In the 2013 IDF global study, a prevalence of $5 \%$ was 
estimated for Nigeria, accounting for 3.9 million cases among persons aged $20-79$ years. ${ }^{8}$ The researchers specifically noted that Nigeria was among countries without up-to-date data on diabetes; hence, the Nigerian estimate was modelled from pooled estimates in Cameroon, due to relatively similar geographic, ethnic and socioeconomic patterns with Nigeria.

Due to the relatively limited epidemiological evidence on the burden of T2DM in Nigeria, ${ }^{11} 14$ the few reported estimates may have been based on advanced modelling and extrapolation of very scarce data, and may not necessarily represent the true burden of the disease in the country. ${ }^{815}$ The WHO reports that there is still need for more research on the burden of diabetes, including country-specific response to diabetes treatment and management, and anthropological and cultural perspectives of diabetes in Africa. ${ }^{76}$ With many research, treatment and management gaps remaining unaddressed, a study focusing on estimating the burden for appropriate public health and policy response has been widely advocated. ${ }^{14}$ We aimed to systematically review the literature on T2DM in Nigeria towards providing national and regional estimates of the prevalence (including undiagnosed cases, persons on treatment and mean fasting plasma glucose (FPG) concentration), hospitalisation and mortality from T2DM in Nigeria.

\section{METHODS}

This study was conducted in accordance with the supplementary MOOSE guidelines of systematic reviews of observational studies. ${ }^{17}$

\section{Search terms and strategy}

Further to an initial scoping exercise with a librarian, Medical Subject Headings (MeSH), search terms and text words that fit into relevant health databases, including MEDLINE, EMBASE, Global Health and Africa Journals Online (AJOL), were identified (table 1).

The databases' search was conducted on 10 February 2017 , and limited to studies published between 1 January 1985 and 31 December 2016, to ensure a relatively consistent diabetes diagnostic criteria not earlier than the WHO 1985 guidelines, which reflects to some degree the current WHO and American Diabetes Association (ADA) case definitions. ${ }^{16}{ }^{18-20}$ Unpublished documents were sourced from Google Scholar and online sites. The abstracts of all studies were reviewed and full texts of relevant studies were accessed. The references of initially accessed studies were further hand-searched for additional studies and data sources. The authors of relevant papers were contacted for missing information.

\section{Eligibility criteria}

Studies were included in the review if they met the following criteria: (1) population based conducted among adults aged 20 years or more, residing in Nigeria, and reporting the prevalence, undiagnosed cases and treatment rates of type 2 diabetes and/or prediabetes, or enough data to compute these estimates; or (2) hospital based and providing information on hospitalisations, complications, death rates or case fatality rates of T2DM in a Nigerian population.

We excluded studies that were (1) primarily on type 1 diabetes; (2) conducted on paediatric population (0-14 years), or among populations of Nigerian origin residing outside Nigeria; (3) hospital based without any report on

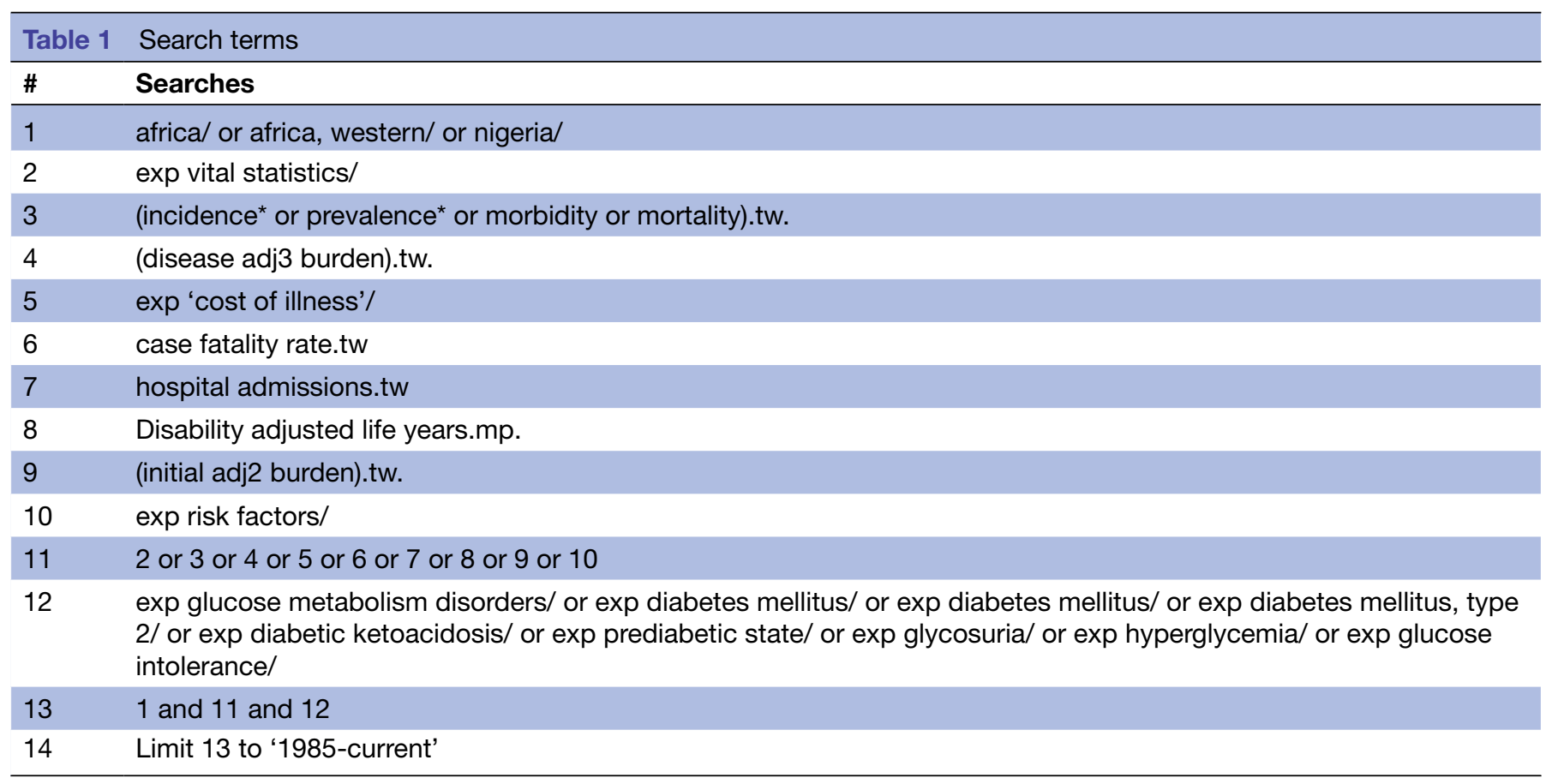


hospitalisations, or deaths due to diabetes complications; (4) solely based on self-reported diagnosis of T2DM; (5) on diabetes, but conducted among persons with co-morbidities; or (6) case series, reviews, commentaries, letters or editorials.

\section{Data extraction}

Literature search and assessment of eligible studies were conducted by two parallel reviewers, with an eligibility guideline to ensure that the selection criteria were consistently applied. Data on location, study period, study design, study setting (urban or rural), sample size, diagnostic criteria and mean age of the population were extracted. These were matched with corresponding data on mean FPG, prevalence, undiagnosed cases, persons on treatment, hospital admission rates, indications for admission, deaths and case fatality rates of T2DM (and for impaired glucose tolerance (IGT) or impaired fasting glucose (IFG) when available). For studies conducted on the same study site, population or cohort, the first chronologically published study was selected, and all additional data from other studies were included in the selected paper. Extracted data were sorted by geopolitical zones in Nigeria, and stored in Microsoft Excel file format.

\section{Quality assessment}

For each full text selected, we further screened for explicit description of methodology, case definitions, blood glucose measurements and generalisability of reported estimates to a larger population within the geopolitical zone. For case definitions, we included studies with diagnosis of (1) diabetes-defined as chronic metabolic condition characterised by raised blood glucose resulting from impairment in secretion of insulin, its action or both, based on FPG levels of $\geq 126 \mathrm{mg} / \mathrm{dL}$ $(7.0 \mathrm{mmoL} / \mathrm{L})$, or 2-hour postprandial glucose (2 hr-pG) reading of $\geq 200 \mathrm{mg} / \mathrm{dL}(11.1 \mathrm{mmoL} / \mathrm{L})$ after a glucose load of $75 \mathrm{~g}$, or random blood glucose (RBG) readings of $\geq 200 \mathrm{mg} / \mathrm{dL}(11.1 \mathrm{mmoL} / \mathrm{L}) ;^{16-20}$ (2) impaired glucose tolerance-defined as elevated non-diabetic levels of blood glucose, based on blood glucose levels of $\geq 140 \mathrm{mg} / \mathrm{dL}(7.8 \mathrm{mmoL} / \mathrm{L}) 2$ hours after consuming $75 \mathrm{~g}$ of glucose $\mathrm{e}^{1618-20}$; and (3) impaired fasting glucosedefined as elevated non-diabetic fasting blood glucose, based on blood glucose levels of $110-125 \mathrm{mg} / \mathrm{dL}$ $(6.1-6.9 \mathrm{mmoL} / \mathrm{L}){ }^{16}{ }^{18-20}$ To allow for fairly consistent pooled estimates, we assessed the appropriateness of statistical analyses employed in the estimation of T2DM prevalence or mortality, and further assessed studies for heterogeneities within and outside various population groups. For the quality grading, we adapted a previously used quality assessment criteria for studies examining the prevalence of chronic diseases (see online supplementary file, for details of the grading criteria). ${ }^{21-24}$ All studies graded as high or moderate quality were included, while the low-quality studies were excluded from the review.

\section{Outcome measures and analysis}

A random-effects meta-analysis, using DerSimonian and Laird Method, ${ }^{25}$ was employed on the individual study estimates to arrive at crude national and regional summary estimates of prevalence, hospital admission and mortality of T2DM in Nigeria. Standard errors were determined from the reported crude estimates and population denominators, assuming a binominal (or Poisson) distribution. Heterogeneity between studies was assessed using I-squared $\left(I^{2}\right)$ statistics, ${ }^{26}$ and subgroup analysis was conducted to identify potential sources of heterogeneity. Population-based data (reporting on T2DM prevalence) and hospital-based data (reporting on hospitalisations, complications and deaths) were analysed separately. Due to limited data, a meta-regression epidemiological model was only applied to T2DM prevalence rates. The model was based on aggregated age from each study (as these had more data points), and adjusted for study period and sample size. Due to demographic and epidemiological transitions, it is understandable that the prevalence rates of diabetes and most chronic diseases may increase with age $;{ }^{10}$ however, the relationship may not be linear. Hence, in our preliminary analyses, we experimented with various models (linear, exponential, polynomial, logarithmic, etc) to determine which was most predictive, that is, the model with the greatest proportion of variance $\left(R^{2}\right)$ of diabetes prevalence as explained by age. This was applied to the final model, and the best fit was used to determine the number of T2DM cases at midpoints of the United Nation (UN) population 5-year age groups for Nigeria for the years 1990 and 2015. Our data analysis has been described in detail in previous studies. ${ }^{27} 28$ All statistical analyses were conducted on STATA (Stata V.13).

\section{Ethical review}

This study is a review of publicly available literature and data on T2DM in Nigeria. Ethical review was therefore not required for this study. The study was however conducted in strict compliance to the MOOSE guidelines.

\section{RESULTS}

\section{Search results}

Our databases' search returned 1664 studies (MEDLINE 505, EMBASE 975, Global Health 132 and AJOL 52). Additional seven studies were identified through Google Scholar and search of reference list of relevant studies. There were 1232 studies assessed after duplicates were removed. On applying the inclusion and exclusion criteria, 1164 studies were excluded, and of the remaining 68 studies, 26 were excluded on applying the quality criteria (table 2, see online supplementary file). A total of 42 studies ${ }^{29-70}$ were finally selected for the review (figure 1).

\section{Study characteristics}

Of the 42 retained studies, 36 were population-based cross-sectional studies reporting on prevalence of T2DM 


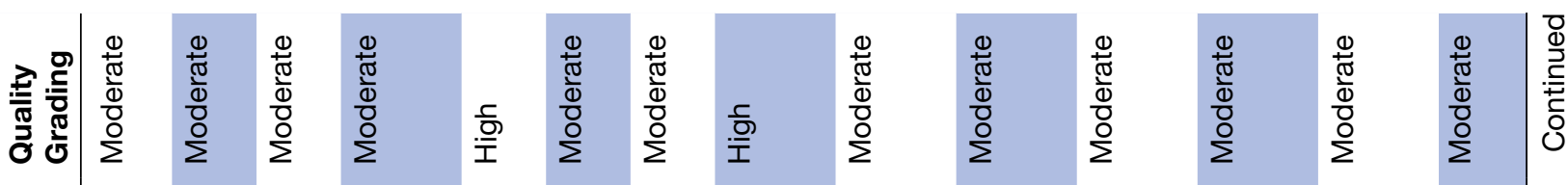

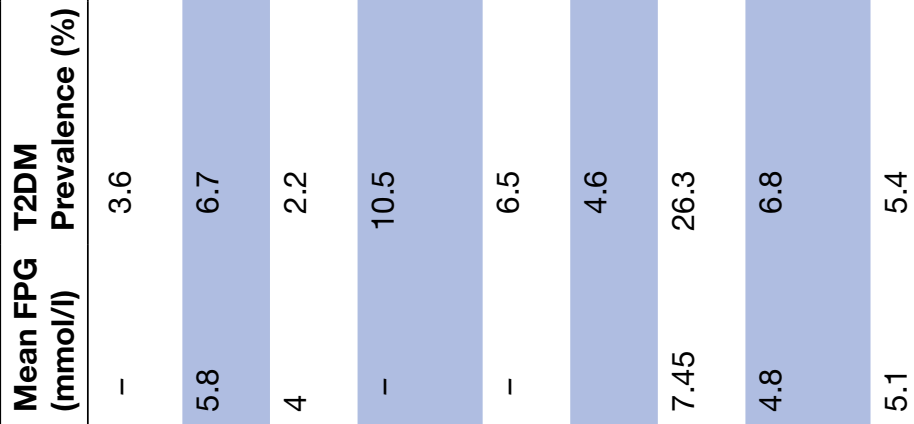

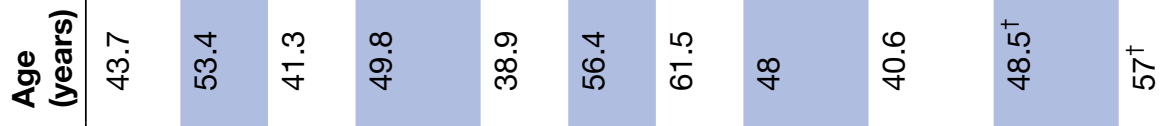

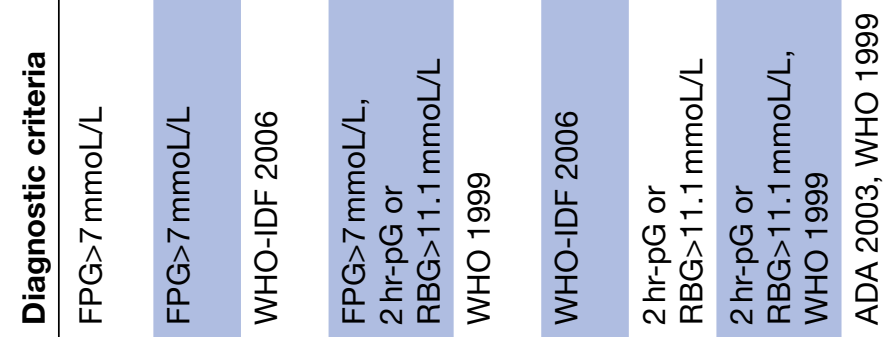

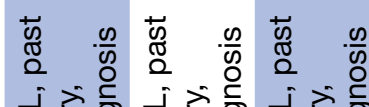

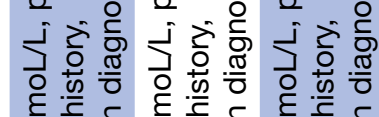

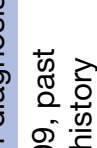

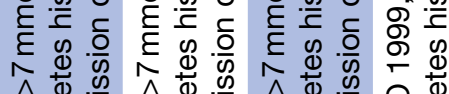

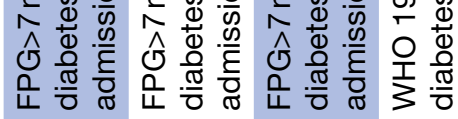

乌̊

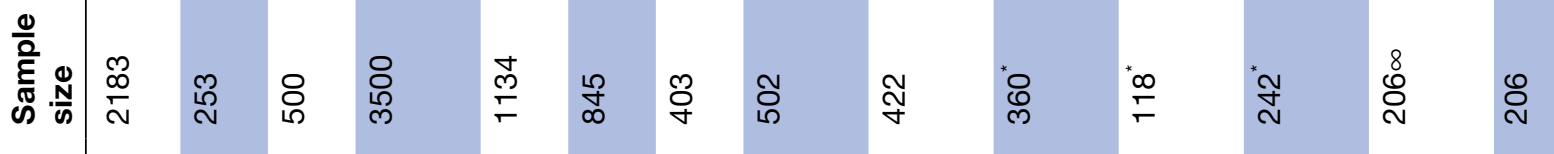

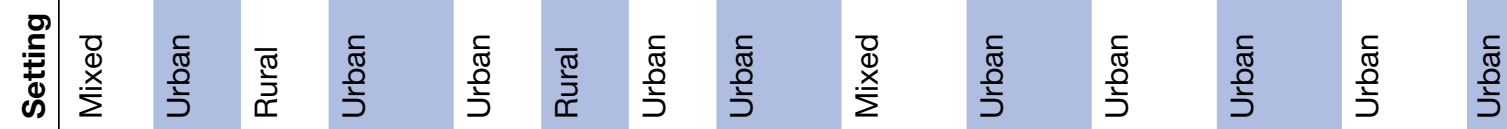

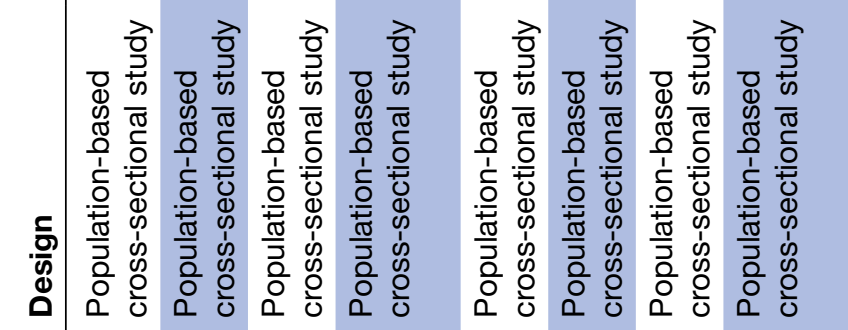

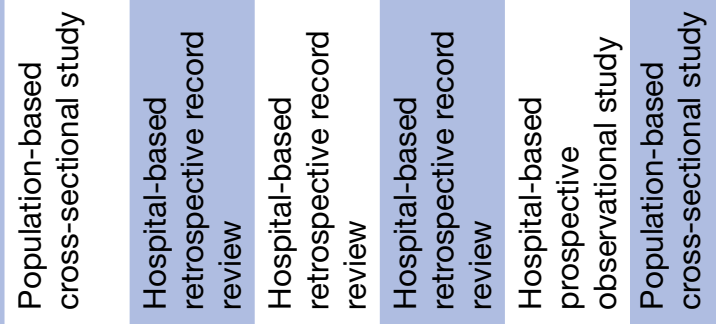

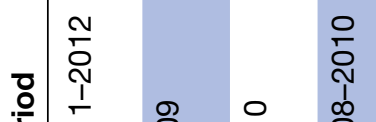

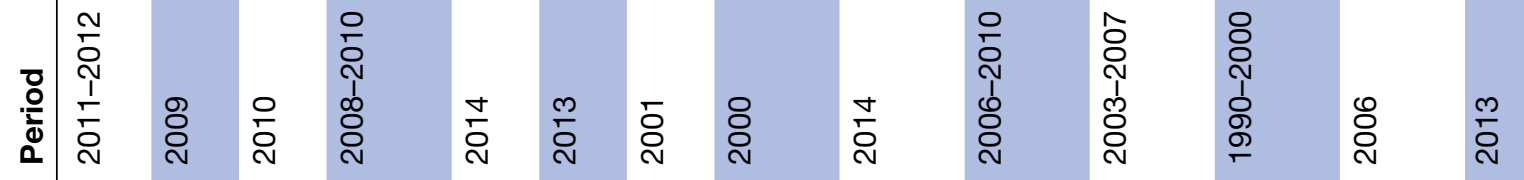

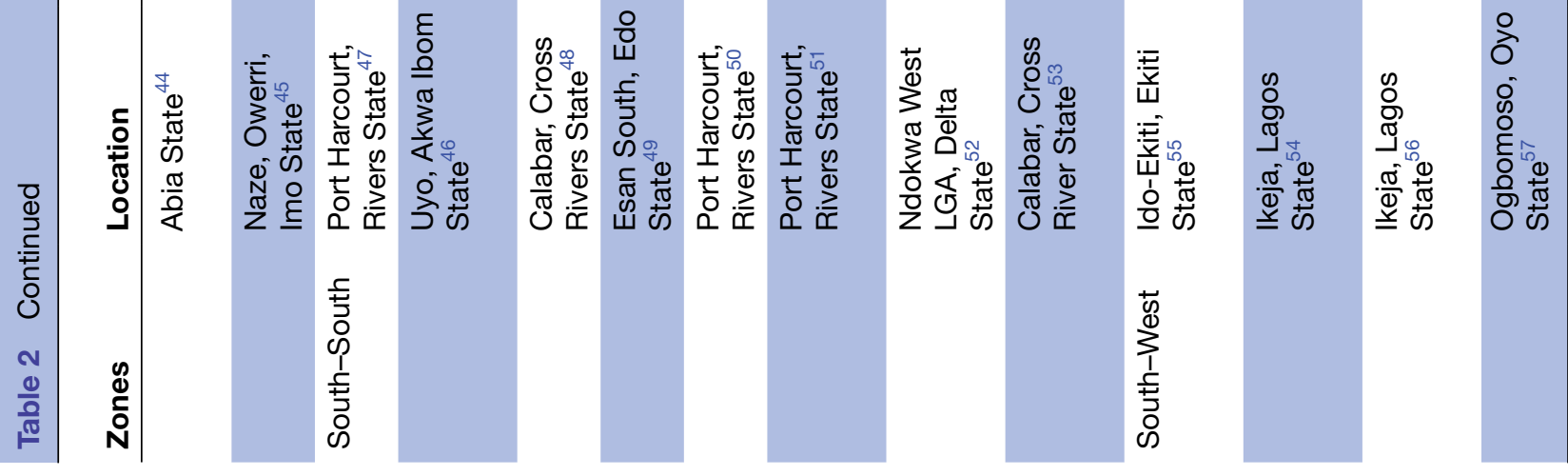

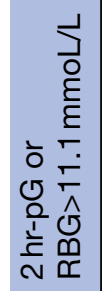

융

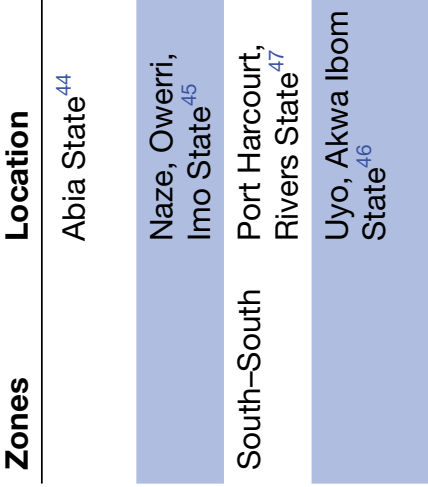




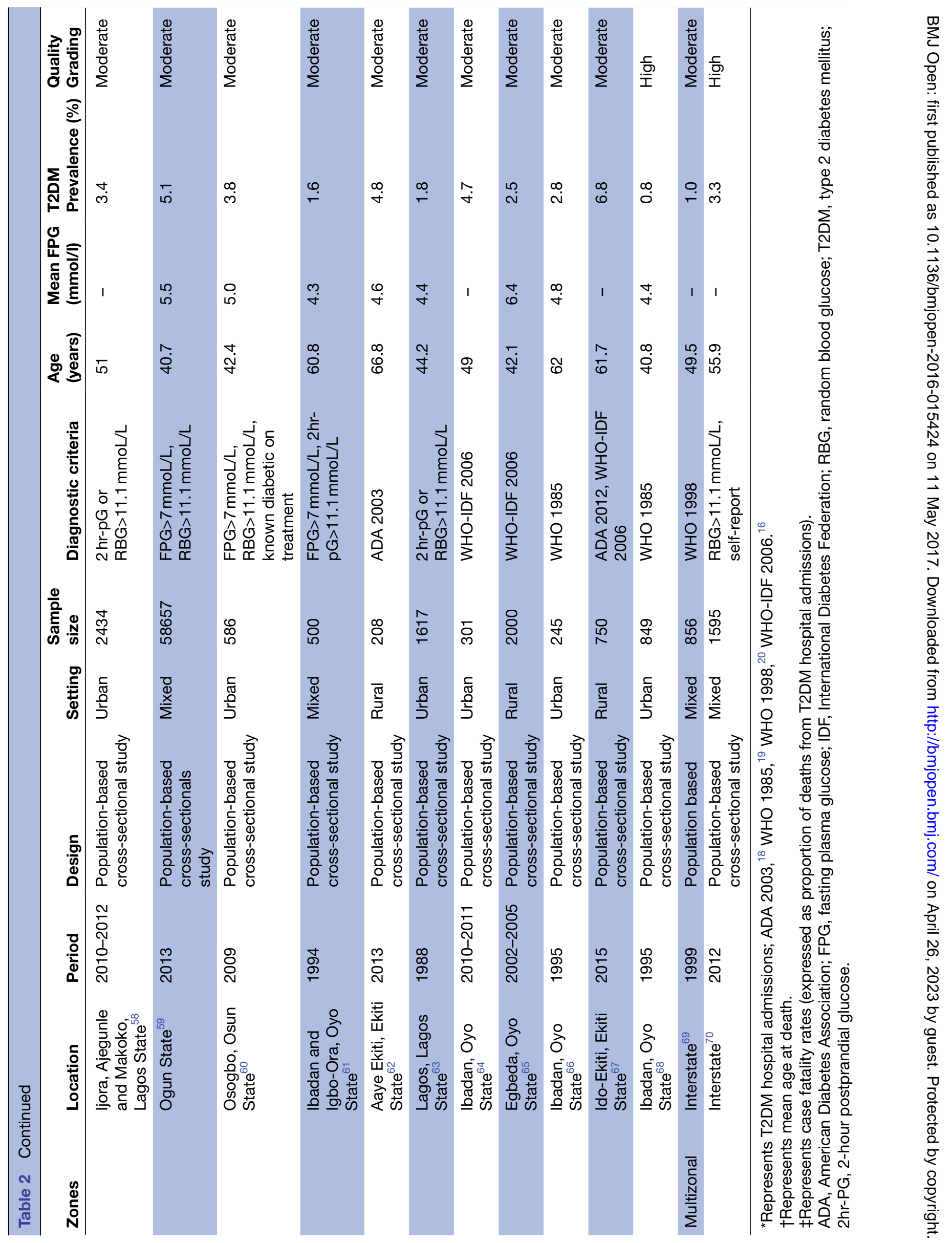




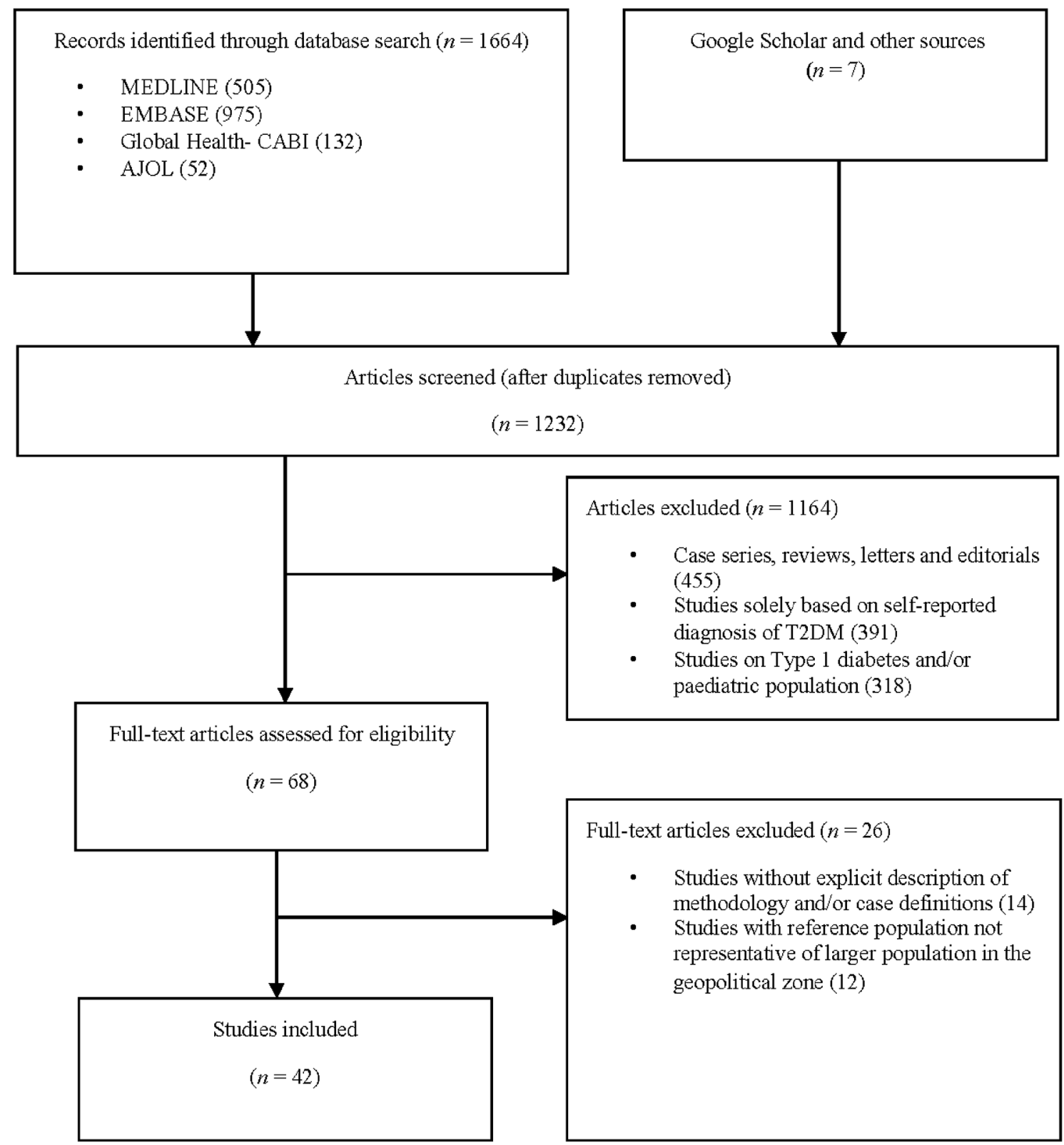

Figure 1 Flow chart of selection of T2DM studies in Nigeria. AJOL, Africa Journals Online; T2DM, type 2 diabetes mellitus.

and 6 were hospital based reporting on hospitalisations, complications and deaths from T2DM (table 2). Most studies (15) were conducted in the South-West region of Nigeria, followed by the South-East and South-South with 8 studies each. The North-West had four studies, North-Central three and North-East two. Two studies were conducted across multiple regions in the country. Study period ranged from 1988 to 2015 , with 20 studies $(47.6 \%)$ conducted after 2010. There were 23 studies $(54.7 \%)$ conducted in urban settings. Excluding hospital-based studies, the total population included in the review was 91320 , with a mean age of 48.9 years (table 2 ). Of the 42 included studies, $4(9.5 \%)$ met the criteria for high level of quality while $38(90.5 \%)$ met the criteria for moderate level of quality. The risk of bias observed across studies included selection bias due to sampling
$(33.3 \%, 14 / 42)$ and non-reporting of response rate $(35.7 \%, 15 / 42)$. Measurement bias was minimal as all the included studies used standard diagnostic criteria to ascertain the prevalence of diabetes. However, the funnel plot was asymmetrical, with this suggestive of publication bias across selected studies (figure 2).

\section{Outcome measures}

Prevalence rates

The lowest prevalence of T2DM was $0.8 \%$ recorded in Ibadan, South-West Nigeria in $1995,{ }^{68}$ and Sokoto, North-West Nigeria in $2013,{ }^{36}$ both with mean ages 38.3 and 40.8 years, respectively. The highest prevalence rates of T2DM were reported among oil company workers in Port Harcourt in $2001(26.3 \% \text {, mean age } 61.5 \text { years })^{50}$ and Uyo in 2010 (10.5\%, mean age 49.8 years), ${ }^{46}$ in 
Funnel plot with pseudo $95 \%$ confidence limits

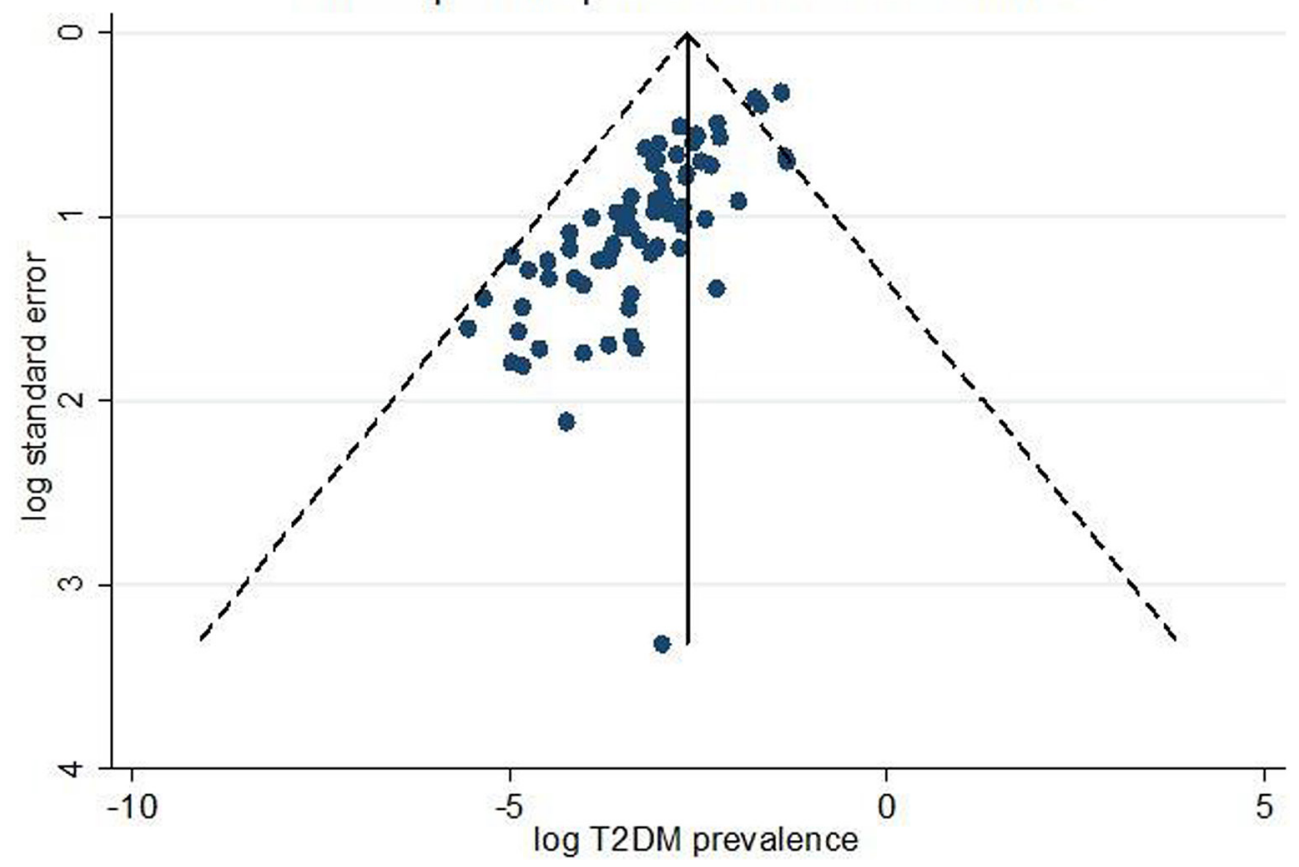

Figure 2 Funnel plot showing distribution of selected studies. T2DM, type 2 diabetes mellitus.

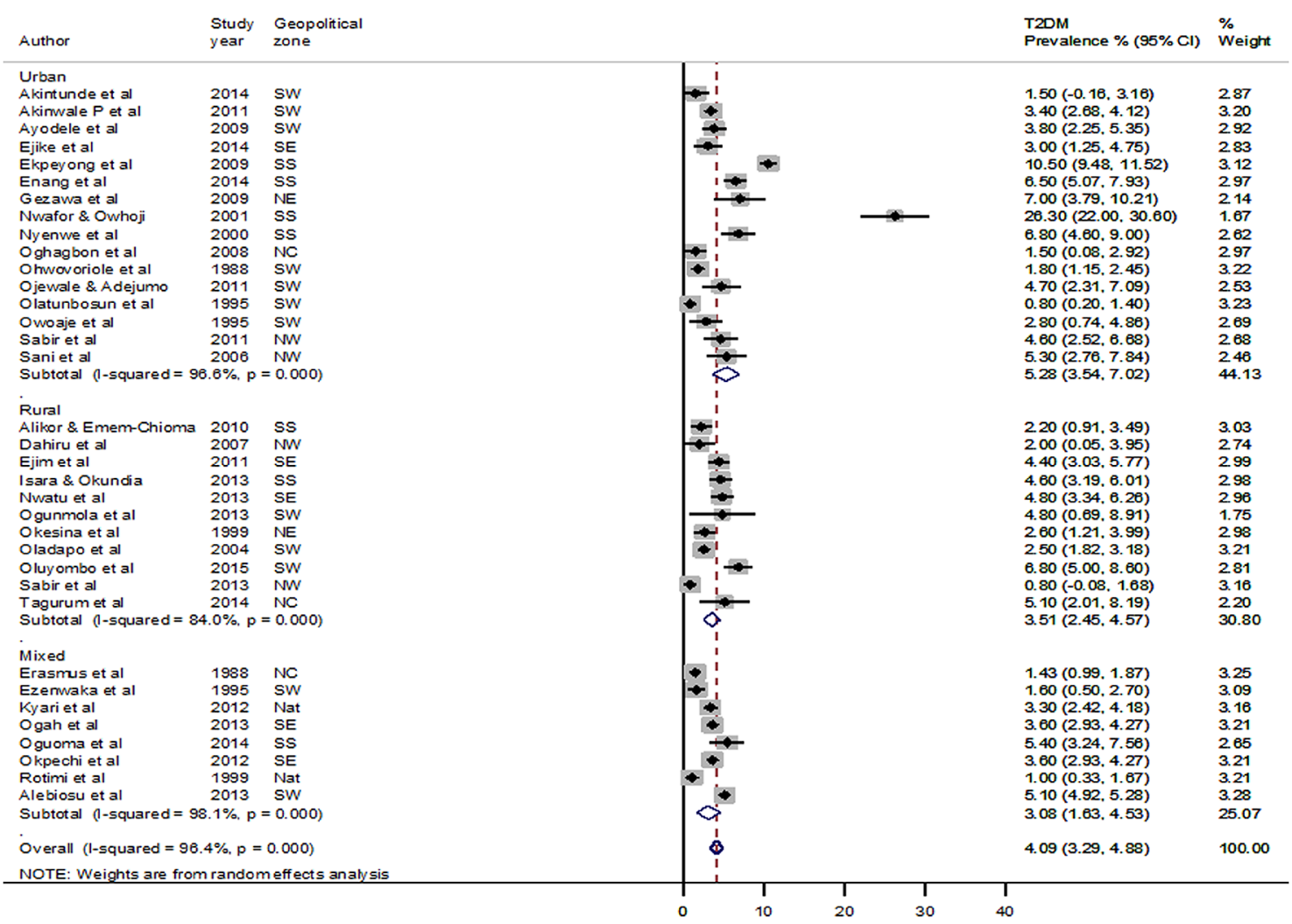

Figure 3 Pooled prevalence rate of T2DM in Nigeria.T2DM, type 2 diabetes mellitus. 
Table 3 Pooled prevalence rates of T2DM, IGT, IFG and mean FPG in Nigeria

\begin{tabular}{|c|c|c|c|c|c|c|}
\hline \multirow[b]{2}{*}{ Extracted data } & \multicolumn{2}{|l|}{ All } & \multicolumn{2}{|l|}{ Men } & \multicolumn{2}{|l|}{ Women } \\
\hline & $\begin{array}{l}\text { Pooled estimate } \\
(95 \% \mathrm{Cl})\end{array}$ & $\mathbf{I}^{2}, \mathrm{p}$ value & $\begin{array}{l}\text { Pooled estimate } \\
\text { (95\% Cl) }\end{array}$ & $I^{2}, p$ value & $\begin{array}{l}\text { Pooled estimate } \\
(95 \% \mathrm{Cl})\end{array}$ & $\mathbf{I}^{2}, \mathrm{p}$ value \\
\hline $\begin{array}{l}\text { Undiagnosed } \\
\text { T2DM (\%) }\end{array}$ & 39.4 (26.0 to 52.7 ) & $\begin{array}{l}92.5 \% \\
p=0.000\end{array}$ & - & - & - & - \\
\hline IGT (\%) & 10.0 (4.5 to 15.6$)$ & $\begin{array}{l}98.0 \% \\
p=0.000\end{array}$ & $10.3(0.7$ to 19.9$)$ & $97.8 \%, p=0.000$ & 11.9 (2.5 to 21.2 ) & $97.4 \%, p=0.000$ \\
\hline IFG (\%) & 5.8 (3.8 to 7.8$)$ & $\begin{array}{l}93.4 \%, \\
p=0.000\end{array}$ & 4.9 (2.6 to 7.2$)$ & $89.7 \%, p=0.000$ & 4.8 (3.0 to 6.6$)$ & $85.1 \%, p=0.000$ \\
\hline
\end{tabular}

${ }^{*}$ Represents percentage of overall T2DM cases; there were no data to pool estimates separately for men and women.

$\mathrm{I}^{2}$ represents the variation in pooled estimate attributable to heterogeneity.

$p$ Value represents level of significance.

FPG, fasting plasma glucose; IFG, impaired fasting glucose; IGT, impaired glucose tolerance; T2DM, type 2 diabetes mellitus.

South-South Nigeria, which is possibly due to the higher socioeconomic statuses in these settings (table 2).

From all studies, the pooled crude prevalence of T2DM was $4.1 \%$ (95\% CI $3.3 \%$ to $4.9 \%$ ), with $4.4 \%$ (95\% CI $3.3 \%$ to $5.9 \%)$ among men and $4.1 \%(95 \%$ CI $3.1 \%$ to $5.1 \%$ ) among women. In the subgroup analysis, the prevalence was higher among urban dwellers at 5.3\% $(95 \%$ CI $3.5 \%$ to $7.0 \%$ ), compared with $3.5 \%$ (95\% CI $2.5 \%$ to $4.6 \%$ ) among rural dwellers (figure 3 , table 3 ).

The South-South region of Nigeria had the highest pooled prevalence of T2DM at $8.5 \%(95 \%$ CI $5.1 \%$ to $11.9 \%)$, followed by the North-East and South-East regions, at $4.6 \%(95 \% \mathrm{CI} 0.3 \%$ to $8.8 \%)$ and $3.7 \%(95 \%$ CI $3.3 \%$ to $4.2 \%$ ), respectively. The North-Central had the lowest pooled prevalence at $2.0 \%$ (95\% CI $0.7 \%$ to $3.3 \%)$. Over the study period, the highest prevalence of T2DM was observed in the period 2000-2009 and 2010-2015 at $6.9 \%(95 \%$ CI $3.9 \%$ to $10.1 \%$ ) and $4.0 \%$ (95\% CI $3.3 \%$ to $4.7 \%$ ), respectively. The pooled prevalence rates in the period 1985-1989 and 1990-1999 were 1.6\% (95\% CI $1.2 \%$ to $1.9 \%$ ) and $1.4 \%$ (95\% CI $0.8 \%$ to $2.1 \%$ ), respectively. In the age group analysis, the highest prevalence was observed in the older age intervals of $60-69,70-79$ and $80+$ years at $6.8 \%(95 \%$ CI $4.1 \%$ to $9.5 \%), 6.4 \%(95 \%$ CI $1.7 \%$ to $11.1 \%$ ) and $9.9 \%$ (95\% CI $2.7 \%$ to $17.2 \%)$, respectively (table 4 ).

Undiagnosed cases of T2DM, expressed as a percentage of all T2DM cases in each study, ranged from $7.8 \%$ in Uyo (South-South) ${ }^{46}$ to $75 \%$ in Dakace village in Zaria (North-West), ${ }^{34}$ with a pooled rate of $39.4 \%(95 \%$ CI $26.0 \%$ to $52.7 \%$ ). T2DM cases on treatment, also expressed as a percentage of all T2DM cases in each study, ranged from $19.6 \%$ in Ido-Ekiti (South-West) ${ }^{67}$ to $50 \%$ in Sokoto (North-West), ${ }^{37}$ with a pooled rate of $32.7 \%(95 \%$ CI $23.5 \%$ to $41.8 \%$ ) (table 3 ).
From all studies, prevalence of IGT ranged from 2.2\% in Ibadan (South-West) ${ }^{68}$ to $19.6 \%$ in Calabar (SouthSouth) ${ }^{48}$ and IFG from $1.1 \%$ in Umudike (South-East) ${ }^{39}$ to $16.9 \%$ in Sokoto (North-West). ${ }^{35}$ The pooled prevalence of IGT was $10.0 \%$ (95\% CI $4.5 \%$ to $15.6 \%$ ), with $10.3 \%$ (95\% CI $0.7 \%$ to $19.9 \%$ ) among men and $11.9 \%$ (95\% CI $2.5 \%$ to $21.2 \%)$ among women. The pooled prevalence of IFG was $5.8 \%$ (95\% CI $3.8 \%$ to $7.8 \%$ ), with $4.9 \%$ (95\% CI $2.6 \%$ to $7.2 \%$ ) among men and $4.8 \%$ (95\% CI $3.0 \%$ to $6.6 \%$ ) among women (figures 4 and 5 , and table 3).

The mean FPG concentration was not too different across studies ranging from $4.0 \mathrm{mmoL} / \mathrm{L}$ in Port Harcourt (South-South) ${ }^{47}$ to $5.9 \mathrm{mmoL} / \mathrm{L}$ in Gindiri-Plateau (North-Central), ${ }^{31}$ with a pooled rate of $5.1 \mathrm{mmoL} / \mathrm{L}$ (95\% CI 4.9 to 5.4) (figure 6). The pooled mean FPG rates among men and women were also almost the same at $4.6 \mathrm{mmoL} / \mathrm{L}$ (95\% CI 4.0 to 5.2$)$ and 4.7 (95\% CI 4.0 to 5.3 ), respectively (table 3 ).

\section{Hospitalisation, mortality and case fatality rates}

Hospital data on T2DM were based on catchment population of the hospital. Crude hospital admission rate ranged from 23.9 to 763.8 per 100000 population, with a pooled rate of 222.6 (95\% CI 133.1 to 312.1 ) per 100000 population. Hyperglycaemic emergencies (mainly diabetic ketoacidosis and hyperosmolar non-ketotic coma), diabetic foot, uncontrolled hypertension and stroke were the most common complications or indications of admission, with pooled rates at $36.1 \%$ (95\% CI $13.9 \%$ to $58.4 \%$ ), $19.6 \%$ (95\% CI $12.3 \%$ to $26.9 \%$ ), $16.7 \%$ (95\% CI $13.4 \%$ to $20.1 \%$ ) and $8.7 \%$ (95\% CI $7.4 \%$ to $10.0 \%$ ), respectively (table 5 ).

The crude mortality rate for T2DM ranged from 0.97 to 105.3 per 100000 population. The overall mortality 
Table 4 Overview of subgroup meta-analysis of type 2 diabetes mellitus (T2DM) in Nigeria

\begin{tabular}{|c|c|c|c|}
\hline \multicolumn{2}{|l|}{ Subgroup } & \multirow{2}{*}{$\begin{array}{l}\text { T2DM prevalence } \%(95 \% \mathrm{Cl}) \\
5.3(3.5 \text { to } 7.0)\end{array}$} & \multirow{2}{*}{$\begin{array}{l}\mathbf{I}^{2}, \mathbf{p} \text { value } \\
96.6 \%, p=0.000\end{array}$} \\
\hline Setting & Urban & & \\
\hline & Rural & $3.5(2.5$ to 4.6$)$ & $84.0 \%, p=0.000$ \\
\hline \multirow[t]{5}{*}{ Geopolitical zone } & North-Central & 2.0 (0.7 to 3.3) & $62.4 \%, p=0.070$ \\
\hline & North-East & $4.6(0.3$ to 8.8$)$ & $83.5 \%, p=0.014$ \\
\hline & South-East & 3.7 (3.3 to 4.2 ) & $0.0 \%, p=0.414$ \\
\hline & South-South & 8.5 (5.1 to 11.9$)$ & $96.8 \%, p=0.000$ \\
\hline & South-West & $3.2(1.9$ to 4.5$)$ & $96.8 \%, p=0.000$ \\
\hline \multirow[t]{2}{*}{ Year } & 1985-1989 & $1.6(1.2$ to 1.9$)$ & $0.0 \%, p=0.354$ \\
\hline & 1990-1999 & $1.4(0.8$ to 2.1$)$ & $54.3 \%, p=0.068$ \\
\hline \multirow[t]{7}{*}{ Age (years) } & $20-29$ & $1.1(0.3$ to 1.9$)$ & $80.3 \%, p=0.000$ \\
\hline & 30-39 & 4.7 (2.9 to 6.6$)$ & $91.9 \%, p=0.000$ \\
\hline & $40-49$ & 4.1 (3.1 to 5.1$)$ & $96.5 \%, p=0.000$ \\
\hline & $50-59$ & 5.1 (3.5 to 6.7$)$ & $92.4 \%, p=0.000$ \\
\hline & $60-69$ & 6.8 (4.1 to 9.5$)$ & $95.0 \%, p=0.000$ \\
\hline & $70-79$ & $6.4(1.7$ to 11.1$)$ & $74.2 \%, p=0.021$ \\
\hline & $80+$ & 9.9 (2.7 to 17.2$)$ & $16.1, p=0.275$ \\
\hline
\end{tabular}

*Study conducted in rural and urban settings with an overall estimate reported.

$\mathrm{I}^{2}$ represents the variation in pooled estimate attributable to heterogeneity.

$\mathrm{p}$ Value represents level of significance.

\begin{tabular}{|c|c|c|c|c|c|}
\hline \multirow[b]{2}{*}{ Author } & Study & \multicolumn{2}{|l|}{ Geopolitical } & \multirow{2}{*}{$\begin{array}{l}\text { IGT } \\
\text { Prevalenœ \% }(95 \% \mathrm{Cl})\end{array}$} & \multirow{2}{*}{$\begin{array}{l}\% \\
\text { Weight }\end{array}$} \\
\hline & year & zone & & & \\
\hline Akintunde et al & 2014 & sw & & $7.80(4.14,11.46)$ & 14.22 \\
\hline Enang et al & 2014 & ss & & $19.60(1729,21.91)$ & 14.77 \\
\hline Nwatu et al & 2013 & SE & & $15.80(13.31,18.29)$ & 14.71 \\
\hline Nyenwe et al & 2000 & ss & 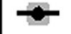 & $2.20(0.92,3.48)$ & 15.04 \\
\hline Olatunbosun et al & 1995 & sw & $*$ & $2.20(1.21,3.19)$ & 15.09 \\
\hline Sabiret al & 2011 & NW & & $14.60(11.09,18.11)$ & 14.30 \\
\hline Sabir et al & 2013 & NW & & $8.00(0.48,15.52)$ & 11.87 \\
\hline \multicolumn{3}{|c|}{ Overall (1-squared $=98.0 \%, p=0.000$ ) } & & $10.03(4.46,15.60)$ & 100.00 \\
\hline \multicolumn{3}{|c|}{ NOTE: Weights are from random effeds analysis } & & & \\
\hline
\end{tabular}

Figure 4 Pooled prevalence rate of IGT in Nigeria. IGT, impaired glucose tolerance. 


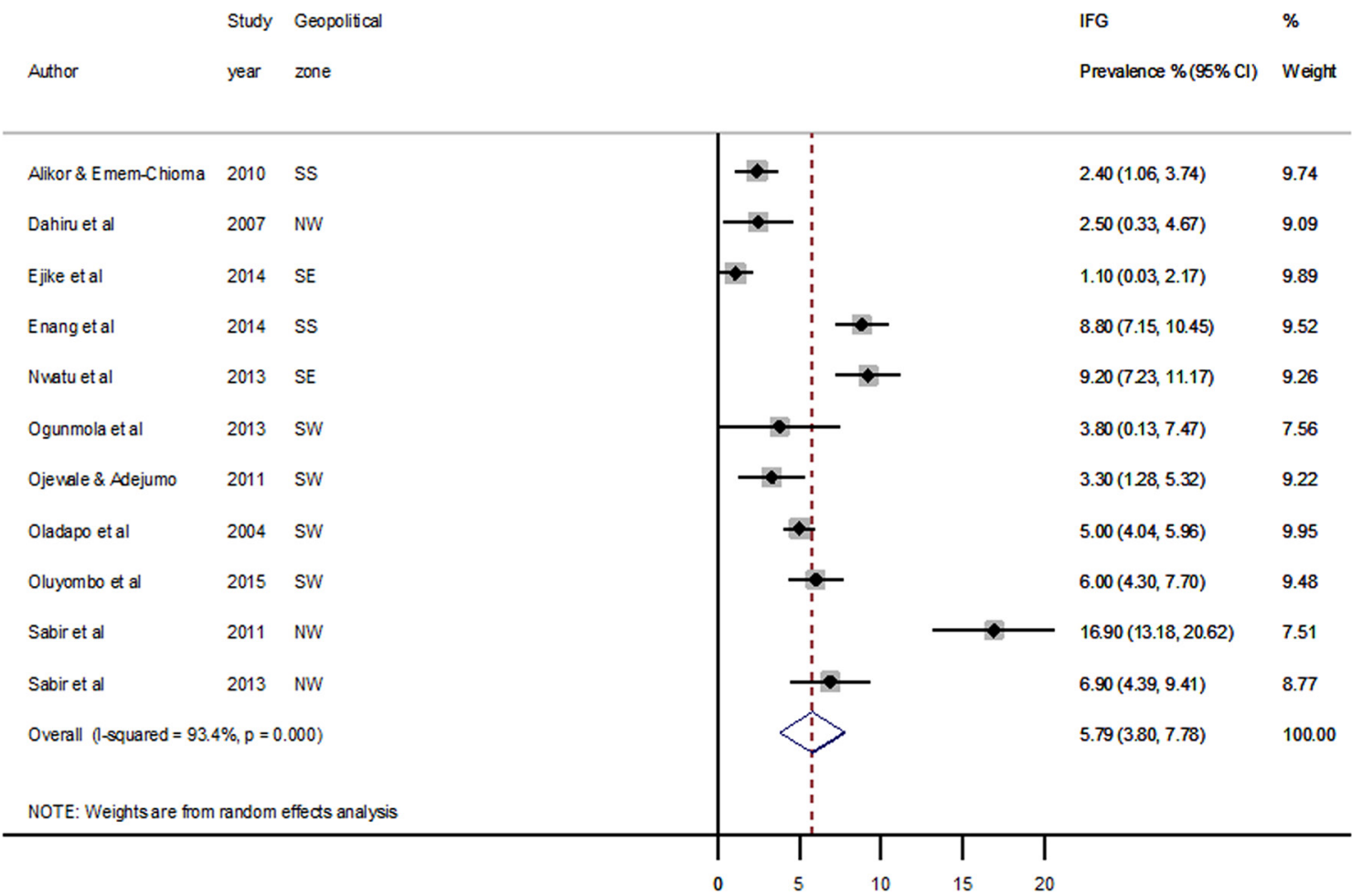

Figure 5 Pooled prevalence rate of IFG in Nigeria. IFG, impaired fasting glucose.

rate from all studies was 30.2 (95\% CI 14.6 to 45.8 ) per 100000 population, with a case fatality rate of $22.0 \%$ (95\% CI $8.0 \%$ to $36.0 \%$ ) (table 5). Assuming sociodemographic and epidemiological changes in Nigeria were fully considered, this would amount to 54297 (26249-82344) deaths in Nigeria in 2015 based on the UN population projections for Nigeria.

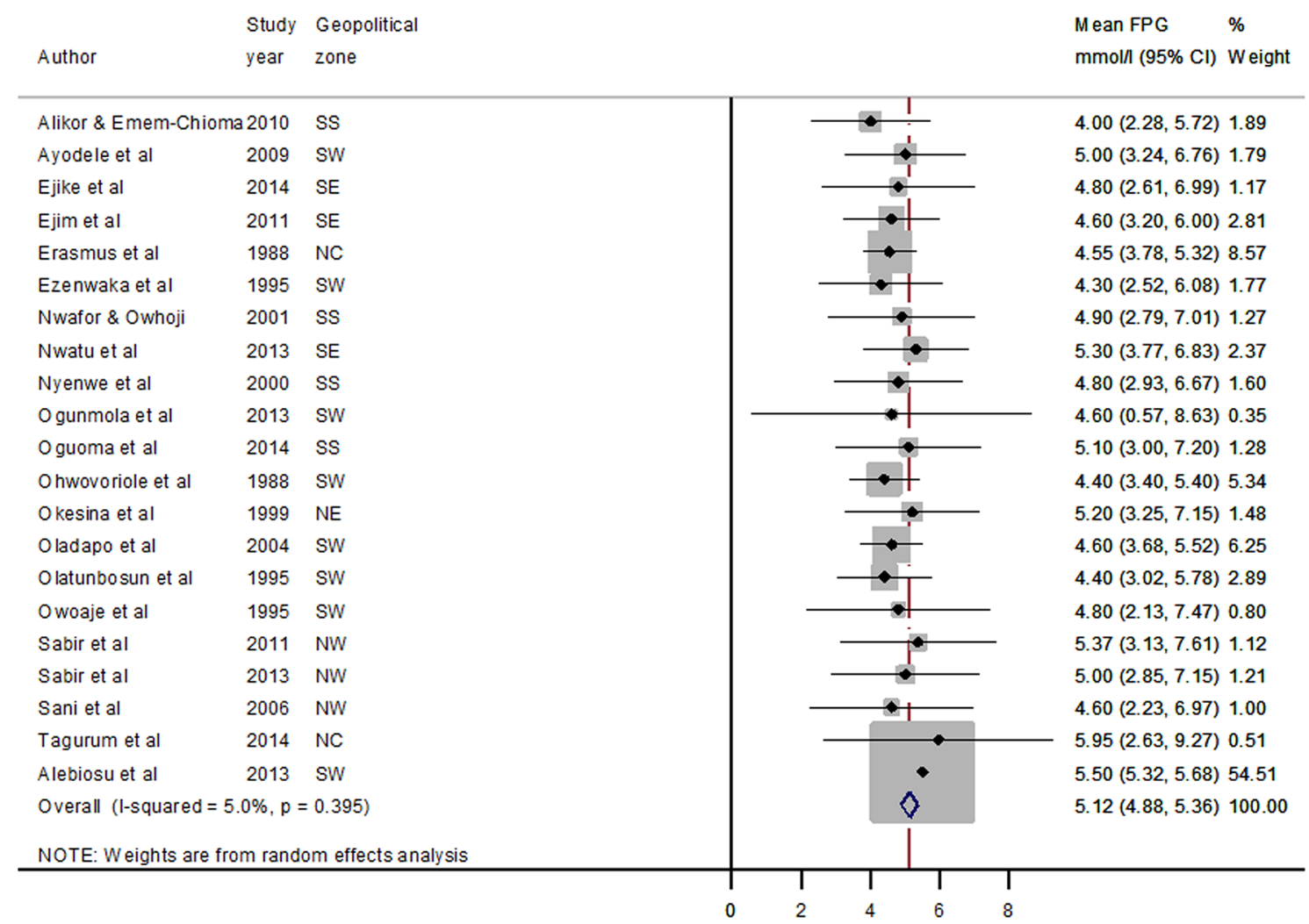

Figure 6 Pooled mean FPG concentration in Nigeria. FPG, fasting plasma glucose. 
Table 5 Hospitalisation, mortality and case fatality rate of type 2 diabetes mellitus (T2DM) in Nigeria

\begin{tabular}{|c|c|c|c|}
\hline \multicolumn{2}{|l|}{ Data } & \multirow{2}{*}{$\begin{array}{l}\text { Pooled estimate }(\mathbf{9 5} \% \mathrm{Cl}) \\
222.6(133.1 \text { to } 312.1)\end{array}$} & \multirow{2}{*}{$\begin{array}{l}\mathbf{I}^{2}, \mathbf{p} \text { value } \\
99.8 \%, p=0.000\end{array}$} \\
\hline \multicolumn{2}{|c|}{ Hospital admission rate (per 100000$)$} & & \\
\hline \multirow{8}{*}{$\begin{array}{l}\text { Indication for hospital } \\
\text { admissions }^{\dagger}(\%)\end{array}$} & Hyperglycaemic emergencies & $36.1(13.9$ to 58.4$)$ & $99.4 \%, p=0.000$ \\
\hline & Diabetic foot & 19.6 (12.3 to 26.9$)$ & $95.7 \%, p=0.000$ \\
\hline & Uncontrolled hypertension & $16.7(13.4$ to 20.1$)$ & $43.6 \%, p=0.170$ \\
\hline & Stroke & $8.7(7.4$ to 10.0$)$ & $0.0 \%, p=0.574$ \\
\hline & Neuropathy & 7.7 (2.3 to 13.2$)$ & $95.1 \%, p=0.000$ \\
\hline & Sepsis & 7.7 (5.3 to 10.1$)$ & $0.0 \%, p=0.732$ \\
\hline & Hypoglycaemia & $5.1(0.9$ to 9.3$)$ & $94.8 \%, p=0.000$ \\
\hline & Nephropathy & 4.2 (3.2 to 5.3$)$ & $27.0 \%, p=0.250$ \\
\hline \multicolumn{2}{|c|}{ Mortality rate $($ per 100000$)$} & 30.2 (14.6 to 45.8$)$ & $99.2 \%, p=0.000$ \\
\hline \multicolumn{2}{|c|}{ Case fatality rate ${ }^{\ddagger}(\%)$} & 22.0 (8.0 to 36$)$ & $99.5 \%, p=0.000$ \\
\hline
\end{tabular}

*Estimate based on reference population of the hospital catchment area. †Percentage of all T2DM hospital admissions.

‡Represents proportion of deaths from T2DM hospital admissions.

\section{Meta-regression model}

The meta-regression modelling, adjusted for study period and sample size, was applied to mean ages and crude prevalence rates from all studies, as these generated more data point. The modelling revealed an increasing prevalence with age $(\mathrm{p}<0.05)$ (table 6 , figure 7$)$.

Using the UN demographic projections for Nigeria, the age-adjusted prevalence rates of T2DM in Nigeria were $2.0 \%$ (95\% CI $1.9 \%$ to $2.1 \%$ ) and $5.7 \%$ (95\% CI $5.5 \%$ to $5.8 \%$ ) in 1990 and 2015, accounting for over 874000 and 4.7 million T2DM cases, respectively, among persons aged 20-79 years. This represents over $440 \%$ increase in overall T2DM cases among persons aged 20-79 years between the twoyears (table 7).

\section{DISCUSSION}

With over $50 \%$ of studies conducted after 2010 , our report suggests that research outputs on T2DM in Nigeria may be gradually increasing, although these may not be evenly distributed across the country as most studies (79\%) originated form the Southern parts of the country. The evidence pool of diabetes, as reported by many experts, still remain limited across Nigeria and many parts of Africa. ${ }^{16}$
Our 1990 estimate is in keeping with the 1997 nationwide diabetes prevalence $(2.2 \%)$ reported by Akinkugbe. ${ }^{12}$ Although Abubakari and Bhopal reported a relatively higher diabetes prevalence $(6.8 \%)$ in $2000,{ }^{71}$ this may be expected as the seven studies included in their report were conducted among persons aged 40 years or older, and mainly in Southern parts of Nigeria, where we also reported higher prevalence rates in contrast to the Northern regions. However, our 2015 prevalence may further indicate an increasing trend in the prevalence of diabetes in Nigeria with over $440 \%$ increase in T2DM cases over the 1990 estimate. This is an important finding in this study, which is in congruence with the estimates reported by Guariguata and colleagues in the IDF global study, with a diabetes prevalence rates of $5 \%$ reported for Nigeria in 2013. ${ }^{8}$ The increasing rate of T2DM has also been documented across several African settings. ${ }^{13-5} 772$ Mbanya and colleagues specifically noted that diabetes prevalence is increasing in sub-Saharan Africa, with a regional prevalence of 2\%-3\% in mid-1990s increasing to about $4.6 \%$ in $2010 .{ }^{10}$ However, the 2015 Nigerian T2DM prevalence reported in this study is higher than the prevalence of adult diabetes reported in Cote d'Ivoire $(2.3 \%)$, Ghana $(1.9 \%)$ and Senegal $(1.8 \%)$, according to

Table 6 Results of the meta-regression modelling

\begin{tabular}{lcccccc}
\hline Prevalence & Coef. & Std. Err. & t & P>t & Upper 95\% Cl & Lower 95\% Cl \\
\hline Age & 0.0898737 & 0.0411097 & 2.19 & 0.032 & 0.0078621 & 0.1718853 \\
Year & 0.1253705 & 0.0630606 & 1.99 & 0.051 & -0.000432 & 0.251173 \\
_cons & -251.0127 & 126.3341 & -1.99 & 0.051 & -503.0424 & 1.017032 \\
\hline
\end{tabular}

Note:REML estimate of between-study variance (tau2) $=16.33$.

$\%$ residual variation due to heterogeneity (I-squared_res) $=92.55 \%$.

Proportion of between-study variance explained (Adj R-squared) $=11.44 \%$.

Joint test for all covariates in Model $(F)=4.90$.

With Knapp-Hartung modification Prob > F=0.0102. 


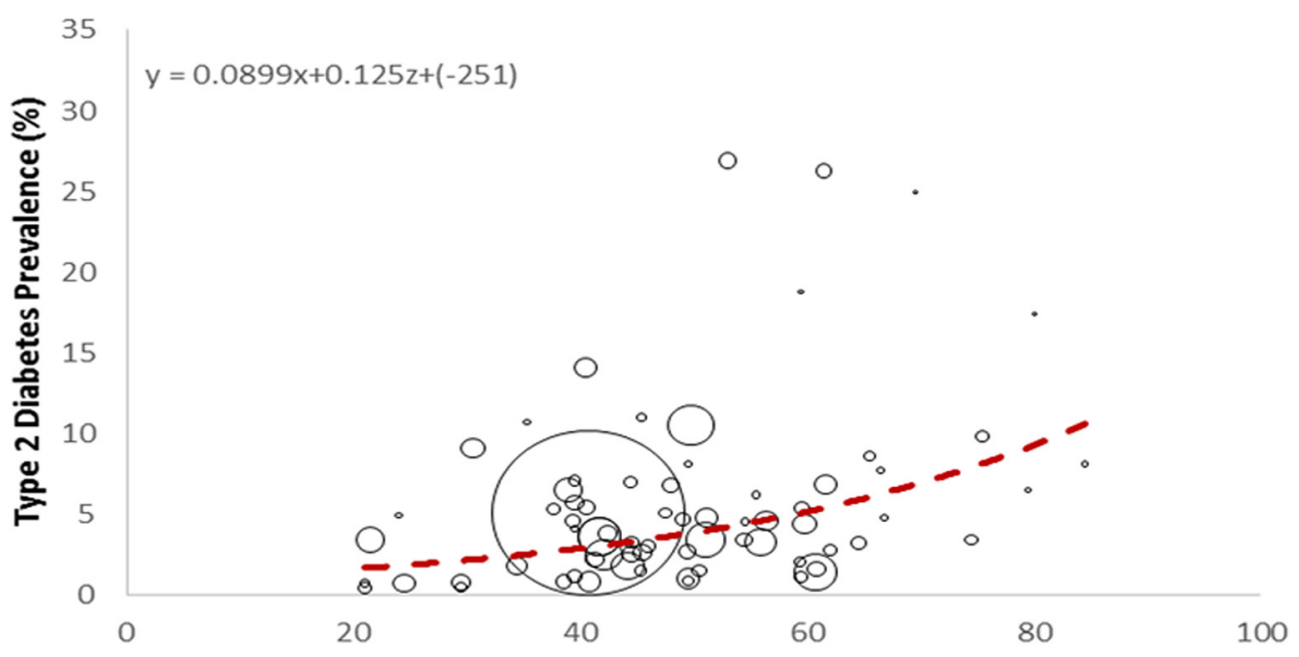

Mean Age (years)

Figure 7 Meta-regression epidemiological modelling showing relationship between prevalence of T2DM and mean age of the population.T2DM, type 2 diabetes mellitus.Note: T2DM prevalence $(\mathbf{y})$, age $(\mathbf{x})$, year $(\mathbf{z})$ and size of the bubble correspond to study sample size. Coefficients of ' $x$ ' and ' $z$ ' are ' 0.0899 ' and ' 0.125 ' for the meta-regressed line, with an intercept of ' -251 '.

the 2015 IDF atlas, ${ }^{6}$ suggesting a relatively higher burden in Nigeria compared with other West African countries.

Meanwhile, the mean country-wide FPG estimated in this study, to the best of our knowledge, is the first reported in Nigeria. At a mean FPG concentration of $5.1 \mathrm{mmoL} / \mathrm{L}$, many people across Nigeria may apparently be approaching the prediabetic states. This therefore may be suggestive of the high IGT and IFG prevalence rates reported in this study. The implication, based on experts' reports, is that regions with relatively low diabetes prevalence but with fairly high prevalence of IGT and IFG may be at an early phase of a diabetes epidemic. ${ }^{73}$ The sex distribution of our estimate is also consistent with many reports, with IGT affecting more women than men, and IFG vice versa. ${ }^{16}$ There is still no sufficient explanation for this sex difference, but increasing prevalence of diabetes observed among African women may be due to the relatively higher

Table 7 Age-adjusted prevalence rates and cases of type 2 diabetes mellitus (T2DM) in Nigeria in 1990 and 2015

\begin{tabular}{|c|c|c|c|c|c|c|}
\hline \multirow[b]{2}{*}{ Age group } & \multicolumn{3}{|l|}{1990} & \multicolumn{3}{|l|}{2015} \\
\hline & $\begin{array}{l}\text { Nigeria } \\
\text { population (000s) }\end{array}$ & Prevalence $^{*}(\%)$ & $\begin{array}{l}\text { T2DM cases } \\
\text { (000s) }\end{array}$ & $\begin{array}{l}\text { Nigeria } \\
\text { population (000s) }\end{array}$ & Prevalence* $^{\star}(\%)$ & $\begin{array}{l}\text { T2DM cases } \\
\text { (000s) }\end{array}$ \\
\hline $20-24$ & 8160.431 & 0.52 & 42.744 & 15981.820 & 3.66 & 584.743 \\
\hline $25-29$ & 6920.907 & 0.97 & 67.361 & 14051.040 & 4.11 & 577.259 \\
\hline $30-34$ & 5833.290 & 1.42 & 82.996 & 12102.270 & 4.56 & 551.597 \\
\hline $35-39$ & 4876.116 & 1.87 & 91.295 & 9982.646 & 5.01 & 499.861 \\
\hline $40-44$ & 4140.621 & 2.32 & 96.137 & 7767.685 & 5.46 & 423.867 \\
\hline $45-49$ & 3579.784 & 2.77 & 99.207 & 6008.701 & 5.91 & 458.783 \\
\hline $50-54$ & 2949.801 & 3.22 & 95.007 & 4993.836 & 6.36 & 381.901 \\
\hline $55-59$ & 2373.829 & 3.67 & 87.127 & 4146.148 & 6.81 & 339.846 \\
\hline $60-64$ & 1861.811 & 4.12 & 76.703 & 3325.733 & 7.25 & 300.795 \\
\hline $65-69$ & 1373.048 & 4.57 & 62.739 & 2554.200 & 7.70 & 256.224 \\
\hline $70-74$ & 905.270 & 5.02 & 45.434 & 1821.521 & 8.15 & 208.264 \\
\hline $75-79$ & 499.574 & 5.47 & 27.318 & 1077.611 & 8.60 & 156.711 \\
\hline $\begin{array}{l}\text { Total } \\
\text { (age adjusted) } \\
\text { 20-79years }\end{array}$ & 43474.480 & 2.01 & 874.068 & 83813.210 & 5.66 & 4739.851 \\
\hline Lower Cl & - & 1.88 & 817.321 & - & 5.50 & 4609.726 \\
\hline Upper Cl & - & 2.14 & 930.354 & - & 5.81 & 4869.547 \\
\hline
\end{tabular}

*Estimate based on meta-regression epidemiological modelling adjusted for year and sample size from each study. 
prevalence of overweight and obesity among women across many African settings, ${ }^{71} 74$ who have wrongly associated this with healthy living, and possibly been contented with the better social status it offered them.

Rapid urbanisation, as an important driver of the increasing burden of T2DM in Africa, ${ }^{10}$ was also confirmed in our report, with prevalence among urban dwellers well above the rural dwellers. Africa, and Nigeria in particular, is experiencing fastest rate of urbanisation globally, with over a third of the population currently residing in urban areas, and this is expected to increase to about $45 \%$ by $2025 .^{756}$ This may also explain the higher T2DM prevalence in Southern Nigeria, a relatively urbanised region compared with the Northern parts, which is in fact further characterised by nomadic lifestyles. Age was another factor noted in our report, with higher prevalence rates observed in the older age groups. Experts have revealed a rising prevalence of diabetes with increasing age, particularly due to continued exposure to several other risks occasioned by prolonged life. ${ }^{1077}$

Our estimated mortality rate from T2DM in Nigeria is relatively lower compared with the overall rate (111.1 per 100000 population) reported for the African region in the WHO global report. ${ }^{7}$ This may be due to the few data points on diabetes deaths in our study, and the fact that individual mortality rates were based on 'large' reference population of the hospital where the study was conducted. In the 2016 WHO diabetes profile, about 28000 diabetes deaths were estimated in Nigeria, stating however that the estimates have high degree of uncertainty as there were no available national mortality data to compute these estimates. ${ }^{15}$ However, our estimates show hospital admissions (from complications) and case fatality rates were comparatively higher in Nigeria, with hyperglycaemic emergencies, diabetic foot and cardiovascular diseases being the most common indications. In Nigeria, there have been reports that many diabetes cases present to health facilities at advanced stages of the disease. ${ }^{14}$ Acute complications of diabetes, mainly diabetic ketoacidosis, hyperosmolar non-ketotic coma and hypoglycaemia, are frequent indications of hospital emergencies in Nigeria, with high mortalities recorded. ${ }^{56}$ High numbers of undiagnosed cases and low treatment rates, as estimated in our study, may also be major factors responsible for the prevalent complications and high mortality rates. Recent reports within Nigeria show that undiagnosed cases of diabetes accounted for about $40 \%$ of the diabetes burden in the country. ${ }^{11}$ According to IDF, about two million undiagnosed diabetes cases were estimated in Nigeria in 2013, with this responsible for over 40000 deaths resulting from diabetes and its complications in the country. ${ }^{8}$ Personal health cost from diabetes, mostly out of pocket, may have also affected hospital visits and use of medications. The lack of a fully functional and equitable national health insurance scheme ${ }^{14}$ means many people with diabetes would prefer to stay at home, visit substandard facilities or patronise traditional herbal healers, due to high cost of treatment and medications, only to present at an advanced stage of the disease to standard health facilities with widespread complications. Kirigia and colleagues estimated that the 7.1 million cases of diabetes reported in Africa in 2000 accounted for a regional economic loss of about 25.5 billion US $\$$, equivalent to about $\$ 3633$ per diabetic case. ${ }^{78}$ The need for insulin and other medications was responsible for the bulk of the direct cost, accounting for about $\$ 8.1$ billion (\$1154/diabetic case).$^{7879}$

While we attempted to provide population representative estimates of the burden of T2DM in Nigeria, we however could have been limited by a number of factors. First, retained studies were not evenly spread across various parts of Nigeria. Most studies selected were conducted in the Southern geopolitical zones of Nigeria, with the Northern zones having nine studies (21.4\%). Data from many studies were also incomplete, as results of some studies, with explicit sampling strategy and study designs, were not always detailed. Besides, data points on age and sex-specific prevalence, including corresponding prevalence for urban and rural settings, were not always provided across studies. There were also sources of heterogeneity from study designs, measurement protocols and individual and population differences across selected studies. However, our selection and quality criteria may have excluded low-quality studies, and we conducted subgroup meta-analyses on selected studies to identify other sources of heterogeneity that may further aid the interpretation of results. There were few data points from hospital-based studies and representative population denominators were not provided. As hospital admissions and mortality rates were based on relatively larger catchment population of the hospital, an underestimation may not be ruled out. Finally, although we controlled for study period and sample population in our modelling, we are aware there could be uncertainties in our reported estimates of T2DM in Nigeria for 1990 and 2015, as varying population contexts, blood glucose measurements, case definitions and social determinants of health, beyond mean age of the population, are important factors that could have affected real-time trends. However, with 42 studies selected across all six geopolitical zones of Nigeria, and a total population of 91320 included, our estimates may still point to a near-precise burden of T2DM in Nigeria.

\section{Conclusion}

Our findings suggest an increasing burden of T2DM in Nigeria with many persons currently undiagnosed, and few known cases on treatment. The rising burden of diabetes has presented huge cost to individuals, society and the Nigerian government. There is still need for more research on T2DM, including specific response to diabetes treatment and management, particularly in Northern Nigeria, where few researches have been conducted to date. We hope our findings may help towards improved research, control, treatment and policy response to diabetes in Nigeria. 
Twitter Follow Davies Adeloye at @davyadeloy

Acknowledgements The authors thank the Covenant University Centre for Research, Innovation and Discovery (CUCRID) for the intellectual support during the conduct of this study.

Contributors DA conceptualised the study. DA, JOI and AA conducted the literature searches. JOI, AA and AVA extracted all data with oversight from DA. DA, NA and EOA performed all statistical analyses. DA and JOI drafted the paper. DA, AVA, AA EOA and GO contributed to writing of the final version of the paper and checked the paper for important intellectual content.

Funding This research received no specific grant from any funding agency in the public,commercial or not-for-profit sectors

Competing interests None declared.

Provenance and peer review Not commissioned; externally peer reviewed. Data sharing statement No additional data available.

Open Access This is an Open Access article distributed in accordance with the Creative Commons Attribution Non Commercial (CC BY-NC 4.0) license, which permits others to distribute, remix, adapt, build upon this work non-commercially, and license their derivative works on different terms, provided the original work is properly cited and the use is non-commercial. See: http://creativecommons.org/ licenses/by-nc/4.0/

(c) Article author(s) (or their employer(s) unless otherwise stated in the text of the article) 2017. All rights reserved. No commercial use is permitted unless otherwise expressly granted.

\section{REFERENCES}

1. International Diabetes Federation. Diabetes Atlas. 1st ed. Brussels, Belgium: International Diabetes Federation, 2000.

2. International Diabetes Federation. Diabetes Atlas. 2nd ed. Belgium: International Diabetes Federation, 2003.

3. International Diabetes Federation. Diabetes Atlas. 3rd ed. Belgium: International Diabetes Federation, 2006.

4. Whiting DR, Guariguata L, Weil C, et al. IDF diabetes atlas: global estimates of the prevalence of diabetes for 2011 and 2030. Diabetes Res Clin Pract 2011;94:311-21.

5. International Diabetes Federation. Diabetes Atlas. 4th ed. Belgium: International Diabetes Federation, 2009.

6. International Diabetes Federation. Diabetes Atlas. 7th ed. Belgium: International Diabetes Federation, 2015.

7. World Health Organisation. Global report on diabetes. 2016 http:// who.int/diabetes/global-report/en/ (accessed 07 April 2016).

8. Guariguata L, Whiting DR, Hambleton I, et al. Global estimates of diabetes prevalence for 2013 and projections for 2035. Diabetes Res Clin Pract 2014;103:137-49.

9. Beran D, Yudkin JS. Diabetes care in sub-Saharan Africa. Lancet 2006;368:1689-95

10. Mbanya JC, Motala AA, Sobngwi E, et al. Diabetes in sub-Saharan Africa Lancet 2010;375:2254-66.

11. Ogbera AO, Ekpebegh C. Diabetes mellitus in Nigeria: the past, present and future. World J Diabetes 2014;5:905-11.

12. Akinkugbe OO. Non-communicable diseases in Nigeria: national survey (Final Report) on hypertension, coronary heart disease, diabetes mellitus, haemoglobinopathies, G6PD deficiency and anaemia. Lagos: Federal Ministry of Health and Social Services National Expert Committee on Non-Communicable Diseases, 1997.

13. Onyemelukwe GC. National survey of noncommunicable diseases (Southwest zone). Abuja: Federal Ministry of Health - National Expert Committee on Non-Communicable Diseases, 2003.

14. Chinenye S, Young E. State of Diabetes Care in Nigeria: a Review. The Nigerian Health Journal 2011;11:101-6.

15. World Health Organisation. Nigeria- Diabetes country profiles. Geneva, Switzerland: World Health Organization, 2016.

16. World Health Organisation. Definition and diagnosis of diabetes mellitus and intermediate hyperglycemia: report of a WHO/IDF consultation. Geneva, Switzerland: WHO, 2006.

17. Stroup DF, Berlin JA, Morton SC, et al. Meta-analysis of observational studies in epidemiology: a proposal for reporting. Meta-analysis of observational studies in Epidemiology (MOOSE) group. JAMA 2000;283:2008-12.

18. Gabir MM, Hanson RL, Dabelea D, et al. The 1997 American Diabetes Association and 1999 World Health Organization criteria for hyperglycemia in the diagnosis and prediction of diabetes. Diabetes Care 2000;23:1108-12.
19. World Health Organization. Diabetes Mellitus: report of a WHO study group. Technical Report Series No.727 Geneva, Switzerland: WHO 1985.

20. Alberti KG, Zimmet PZ. Definition, diagnosis and classification of diabetes mellitus and its complications. Part 1: diagnosis and classification of diabetes mellitus provisional report of a WHO consultation. Diabet Med 1998;15:539-53.

21. Stanifer JW, Jing B, Tolan S, et al. The epidemiology of chronic kidney disease in sub-Saharan Africa: a systematic review and metaanalysis. Lancet Glob Health 2014;2:e174-e181.

22. Pai M, McCulloch M, Gorman JD, et al. Systematic reviews and meta-analyses: an illustrated, step-by-step guide. Natl Med J India 2004;17:86-95.

23. Guyatt GH, Rennie D. Users' guides to the medical literature: a manual for evidence-based clinical practice. Chicago: AMA Press, 2002.

24. Jüni $P$, Altman DG, Egger M. Systematic reviews in health care: assessing the quality of controlled clinical trials. BMJ 2001;323:42-6.

25. DerSimonian R, Laird N. Meta-analysis in clinical trials. Control Clin Trials 1986;7:177-88.

26. Higgins JP, Green S. Cochrane Handbook for Systematic Reviews of Interventions. Cochrane Collaboration: Oxford, 2011.

27. Adeloye D, Basquill C, Aderemi AV, et al. An estimate of the prevalence of hypertension in Nigeria: a systematic review and metaanalysis. J Hypertens 2015;33:230-42.

28. Adeloye D, Basquill C. Estimating the prevalence and awareness rates of hypertension in Africa: a systematic analysis. PLoS One 2014;9:e104300.

29. Erasmus RT, Fakeye T, Olukoga O, et al. Prevalence of diabetes mellitus in a Nigerian population. Trans $R$ Soc Trop Med Hyg 1989;83:417-8.

30. Oghagbon EK, Okesina AB, Biliaminu SA. Prevalence of hypertension and associated variables in paid workers in Ilorin, Nigeria. Niger $J$ Clin Pract 2008;11:342-6.

31. Tagurum YO, Okoh EO, Inalegwu E, et al. Non-communicable diseases: prevalence and risk factors among adults in a rural community in Plateau State, Nigeria. Int $J$ Biomed Res 2015;6:228-34.

32. Gezawa ID, Puepet FH, Mubi BM, et al. Socio-demographic and anthropometric risk factors for type 2 diabetes in Maiduguri, NorthEastern Nigeria. Sahel Medical Journal 2015;18:1-7.

33. Okesina AB, Oparinde DP, Akindoyin KA, et al. Prevalence of some risk factors of coronary heart disease in a rural nigerian population. East Afr Med J 1999;76:212-6.

34. Dahiru T, Jibo A, Hassan AA, et al. Prevalence of diabetes in a semiurban community in Northern Nigeria. Niger J Med 2008;17:414-6.

35. Sabir AA, Isezuo SA, Ohwovoriole AE. Dysglycaemia and its risk factors in an Urban Fulani population of Northern Nigeria. West Afr $J$ Med 2011;30:325-30.

36. Sabir A, Ohwovoriole A, Isezuo S, et al. Type 2 diabetes mellitus and its risk factors among the rural Fulanis of Northern Nigeria. Ann Afr Med 2013;12:217-22.

37. Sani MU, Wahab KW, Yusuf BO, et al. Modifiable cardiovascular risk factors among apparently healthy adult Nigerian population - a cross sectional study. BMC Res Notes 2010;3:11.

38. Aguocha BU, Ukpabi JO, Onyeonoro UU, et al. Pattern of diabetic mortality in a tertiary health facility in south-eastern Nigeria. AJDM 2013;21:14-16

39. Ejike C, Uka NK, Nwachukwu SO. Diabetes and pre-diabetes in adult Nigerians: prevalence, and correlations of blood glucose concentrations with measures of obesity. Afr J Biochem Res 2015;9:55-60.

40. Ejim EC, Okafor $\mathrm{Cl}$, Emehel A, et al. Prevalence of cardiovascular risk factors in the middle-aged and elderly population of a Nigerian rural community. J Trop Med 2011;2011:1-6.

41. Ngwogu KO, lek M, Ngwogu AC. Morbidity pattern of diabetic admissions at the Abia State University Teaching Hospital, Aba, Nigeria. IJCR 2012;1:49-53.

42. Nwatu CB, Ofoegbu EN, Unachukwu CN, et al. Prevalence of prediabetes and associated risk factors in a rural Nigerian community. Int J Diab Dev Ctries 2015;2015:1-7.

43. Ogah OS, Madukwe OO, Onyeonoro UU, et al. Cardiovascular risk factors and non-communicable diseases in Abia state, Nigeria: report of a community-based survey. Int J Med Biomed Res 2013;2:57-68.

44. Okpechi IG, Chukwuonyel Tiffin N, et al. Blood pressure gradients and cardiovascular risk factors in urban and rural populations in Abia State South Eastern Nigeria using the WHO STEPwise approach. PLoS One 2013;8:e73403.

45. U. Osuji C, A. Nzerem B, E. Dioka C, et al. Prevalence of diabetes mellitus in a group of women attending 'August meeting' at Naze South East Nigeria. J Diabetes Mellitus 2012;2:321-6. 
46. Ekpenyong CE, Akpan UP, Ibu JO, et al. Gender and age specific prevalence and associated risk factors of type 2 diabetes mellitus in Uyo metropolis, South Eastern Nigeria. Diabetologia Croatica 2012;41:17-28.

47. Alikor CA, Emem-Chioma PC. Epidemiology of diabetes and impaired fasting glucose in a rural community of nigerian Niger delta region. Niger J Med 2015;24:114-24.

48. Enang OE, Otu AA, Essien OE, et al. Prevalence of dysglycemia in Calabar: a cross-sectional observational study among residents of Calabar, Nigeria. BMJ Open Diabetes Res Care 2014;2:e000032.

49. Isara AR, Okundia PO. The burden of hypertension and diabetes mellitus in rural communities in southern Nigeria. Pan Afr Med J $2015 ; 20$.

50. Nwafor A, Owhoji A. Prevalence of diabetes mellitus among Nigerians in Port Harcourt correlates with socioeconomic status. J Appl Sci Environ Mgmt 2001;5:75-7.

51. Nyenwe EA, Odia OJ, Ihekwaba AE, et al. Type 2 diabetes in adult Nigerians: a study of its prevalence and risk factors in Port Harcourt, Nigeria. Diabetes Res Clin Pract 2003;62:177-85.

52. Oguoma VM, Nwose EU, Skinner TC, et al. Prevalence of cardiovascular disease risk factors among a Nigerian adult population: relationship with income level and accessibility to CVD risks screening. BMC Public Health 2015;15:397.

53. Umoh VA, Otu AA, Enang OE, et al. The pattern of diabetic admissions in UCTH Calabar, South Eastern Nigeria: a five year review. TNHJ 2012;12:7-11.

54. Ogbera O. Burden of diabetic illness in an urban hospital in Nigeria. Trop Doct 2007;37:153-4.

55. Ajayi EA, Ajayi AO. Pattern and outcome of diabetic admissions at a federal medical center: a 5-year review. Ann Afr Med 2009;8:271-5.

56. Ogbera AO, Chinenye S, Onyekwere A, et al. Prognostic indices of diabetes mortality. Ethn Dis 2007;17:721-5.

57. Akintunde AA, Salawu AA, Opadijo OG. Prevalence of traditional cardiovascular risk factors among staff of Ladoke Akintola University of Technology, Ogbomoso, Nigeria. Niger J Clin Pract 2014;17:750-5

58. Pheabian Akinwale O, John Oyefara L, Adejoh P, et al. Survey of hypertension, Diabetes and Obesity in three Nigerian Urban Slums. Iran J Public Health 2013;42:972-9.

59. Alebiosu OC, Familoni OB, Ogunsemi OO, et al. Community based diabetes risk assessment in ogun state, Nigeria (World Diabetes Foundation project 08-321). Indian J Endocrinol Metab 2013;17:653-8.

60. Ayodele OE, Okunola OO, Afolabi MO, et al. Prevalence of hypertension, diabetes and chronic kidney disease in participants of the 2009 World Kidney Day screening exercise in Southwest Nigeria. HKJN 2011;13:55-63.

61. Ezenwaka CE, Akanji AO, Akanji BO, et al. The prevalence of insulin resistance and other cardiovascular disease risk factors in healthy elderly southwestern Nigerians. Atherosclerosis 1997;128:201-11.

62. Ogunmola OJ, Olaifa AO, Oladapo OO, et al. Prevalence of cardiovascular risk factors among adults without obvious cardiovascular disease in a rural community in Ekiti State, Southwest Nigeria. BMC Cardiovasc Disord 2013;13:89.

63. Ohwovoriole AE, Kuti JA, Kabiawu SI. Casual blood glucose levels and prevalence of undiscovered diabetes mellitus in Lagos Metropolis Nigerians. Diabetes Res Clin Pract 1988;4:153-8.

64. Ojewale LY, Adejumo PO. Type 2 Diabetes Mellitus and impaired fasting blood glucose in Urban South Western Nigeria. Int J Diabetes \& Metab 2012;21:9-12.

65. Oladapo OO, Salako L, Sodiq O, et al. A prevalence of cardiometabolic risk factors among a rural Yoruba south-western nigerian population: a population-based survey. Cardiovasc $J$ Afr 2010;21:26-31.

66. Owoaje EE, Rotimi CN, Kaufman JS, et al. Prevalence of adult diabetes in Ibadan, Nigeria. East Afr Med J 1997;74:299-302.

67. Oluyombo R, Olamoyegun MA, Olaifa O, et al. Cardiovascular risk factors in semi-urban communities in southwest Nigeria: patterns and prevalence. J Epidemiol Glob Health 2015;5:167-74.

68. Olatunbosun ST, Ojo PO, Fineberg NS, et al. Prevalence of diabetes mellitus and impaired glucose tolerance in a group of urban adults in Nigeria. J Natl Med Assoc 1998;90:293-301.

69. Rotimi CN, Cooper RS, Okosun IS, et al. Prevalence of diabetes and impaired glucose tolerance in Nigerians, Jamaicans and US blacks. Ethn Dis 1999;9:190-200.

70. Kyari F, Tafida A, Sivasubramaniam S, et al. Prevalence and risk factors for diabetes and diabetic retinopathy: results from the Nigeria national blindness and visual impairment survey. BMC Public Health 2014;14:1299.

71. Abubakari AR, Bhopal RS. Systematic review on the prevalence of diabetes, overweight/obesity and physical inactivity in Ghanaians and Nigerians. Public Health 2008;122:173-82.

72. Wild S, Roglic G, Green A, et al. Global prevalence of diabetes: estimates for the year 2000 and projections for 2030. Diabetes Care 2004;27:1047-53.

73. Mbanya JC, Kengne AP, Assah F. Diabetes care in Africa. Lancet 2006;368:1628-9.

74. Ogbera AO. Prevalence and gender distribution of the metabolic syndrome. Diabetol Metab Syndr 2010;2:1.

75. World Bank. World development report. New York: Oxford University Press for the World Bank, 1993.

76. United Nations. World Population Prospects, the 2010 Revision: definition of regions. 2012 http://esa.un.org/unpd/wpp/Excel-Data/ definition-of-regions.htm (accessed 24 July 2012)).

77. Aspray TJ, Unwin N. Diabetes in sub-Saharan Africa. Adv Exp Med Biol 2001;498:21-6.

78. Kirigia JM, Sambo HB, Sambo LG, et al. Economic burden of diabetes mellitus in the WHO African region. BMC Int Health Hum Rights 2009;9:6.

79. Mbanya JC, Mbanya D. Diabetes cost in sub-Saharan Africa. $J$ Cardiovasc Risk 2003;10:191-3. 